\title{
Acid Mucopolysaccharide (AMPS) Abnormality in Multiple Sulfatase Deficiency: Chemical Compositions of AMPS in Urine and Liver
}

\author{
YOSHIKATSU ETO, ${ }^{(29)}$ TOSHIHARU TOKORO, TERUO HANDA, NORBERT N. HERSCHKOWITZ, \\ AND OWEN M. RENNERT \\ Department of Pediatrics, Tokyo Jikei University School of Medicine, Nishishinbashi, Minato-ku, Tokyo, Japan \\ [Y.E., T.T., T.H.]; Department of Pediatrics, University of Berne, Berne, Switzerland, [N.N.H.]; and Department of \\ Pediatrics, Oklahoma Children's Memorial Hospital, University of Oklahoma Health Sciences Center, Oklahoma \\ City, Oklahoma, USA [O.M.R.]
}

\begin{abstract}
Summary
Extensive chemical analyses of acid mucopolysaccharides (AMPS) were carried out in the urine and tissues (liver and brain) from a Japanese patient and two European patients with multiple sulfatase deficiency (MSD). The Japanese patient with MSD contained excessive quantities of heparan sulfate and moderately increased chondroitin sulfate $A / C$. Urinary excretion of AMPS in MSD heterozygotes was increased 2-fold compared to our controls. The urinary pattern of AMPS in the mother of the MSD patient showed an increase of $18 \%$ heparan sulfate and $36 \%$ dermatan sulfate whereas the urinary excretion pattern in the father was increased $21 \%$ for heparan sulfate as contrasted to controls (chondroitin sulfate $A, 50-52 \%$; chondroitin sulfate $C, 38$ $46 \%$; and heparan sulfate, $3-10 \%$ ).

Seventy-five \% of the AMPS and the MSD liver was heparan sulfate rather than dermatan sulfate. The degree of accumulation of AMPS in the MSD liver was 30-50 times that of the control. Cerebral gray matter from the MSD patient contained 30-40 times that of control (relative increase of heparan and dermatan sulfate) whereas only a 5-fold increase was observed in white matter. It seems that a major site of accumulated AMPS appears to be in the gray matter.

Carbohydrate analysis of the AMPS obtained from MSD urine and tissues was performed by: enzyme digestion with testicular hyaluronidase, heparitinase and chondroitinase $A B C$, cellulose acetate electrophoresis, Dowex-1 column chromatography and amino sugar analysis by amino acid analyzer. These findings indicate that the major accumulated AMPS in MSD urine and liver is heparan sulfate and thus, the predominant AMPS metabolic defect in MSD is heparan sulfate degradation.
\end{abstract}

\section{Speculation}

The accumulation of negatively charged AMPS, particularly the increased heparan sulfate in the nervous system of patients with MSD, leads to cellular dysfunction resulting in changes in the net charge of neuronal cells.

Multiple sulfatase deficiency (MSD) is considered to be an autosomal recessively inherited disorder characterized by severe neurologic symptoms, gargoyle-like face, mild hepatosplenomegaly, ichthyosis and skeletal abnormalities $(1,20)$. Biochemically, the accumulations of sulfatide, acid mucopolysaccharides (AMPS) and cholesterol sulfate accompanied with deficiencies of arylsulfatases A, B and C, steroid sulfatase and acid mucopolysaccharide sulfatases ( $\alpha$-iduronosulfatase, heparan $\mathrm{N}$-sulfatase, $\mathrm{N}$-acetylgalactosamine-4-sulfatase, N-acetylgalactosamine-6-sulfatase, $\mathrm{N}$ acetylglucosamine-6-sulfatase) have been described in patient's tissues and cultured skin fibroblasts $(1,2,10,20,21)$. This disorder is of considerable theoretical interest and distinct from classical MSD, because it appears to be a single mutant gene disorder in which there are deficient activities of at least seven different enzymes involving the genes for enzymes localized in autosomal and X-chromosomes (10).

However, few descriptions provide detailed chemical analysis of AMPS and other complex carbohydrates in MSD tissues and urine. Thus, it is worthwhile to delineate the exact chemical nature of accumulated compounds so as to enhance understanding of the consequences of the multiple sulfatase deficiencies.

This report presents the detailed chemical analysis of complex carbohydrates including AMPS in liver and urine.

\section{MATERIALS AND METHODS}

Tissues and urine specimens. Autopsied tissues of two cases with MSD were kindly provided by Rampini (Department of Pediatrics, University of Zurich, Switzerland) and reported elsewhere (22). The chemical and enzymic studies of these cases were reported previously $(10-12)$. The chemical analysis of urine specimens was carried out in the Japanese case of MSD. The clinical and biochemical observations of this case will be reported (13). One or more 24-h urine collections were obtained from patients

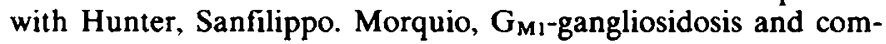
pared to specimens from 10 normal children aged from 1-15 years of age.

Preparation of AMPS in urine and tissues. Isolation of urinary AMPS was performed by precipitation with $5 \%$ cetylpyridinium chloride. AMPS-uronic acid was measured by the carbazol method of Dische (8). The procedure was performed as described by DiFerrante (6). Crude tissue AMPS were prepared by methods reported previously $(18,19)$.

Dowex-1 column chromatography. CPC-precipitated fractions obtained from urine and tissues were subjected to fractionation by Dowex-1 column chromatography (1-X2; 200-400 mesh, $\mathrm{Cl}^{1-}$ form) $(1 \times 8 \mathrm{~cm})$. The stepwise elution was accomplished by increasing salt concentration up to $3.0-5.0 \mathrm{M} \mathrm{NaCl}$ (24). Elution was monitored by measuring uronic acid content.

Electrophoresis. Electrophoresis on Sepharax membrane (Joko Sangyo, Tokyo, Japan) was carried out by Wessler's method (27) in $0.1 \mathrm{M}$ barium acetate for $2 \mathrm{~h}$ with a potential gradient of $15 \mathrm{~V} /$ $\mathrm{cm}$ and in $0.1 \mathrm{M}$ calcium acetate, $\mathrm{pH} 7.0$ at $0.5 \mathrm{~mA} / \mathrm{cm}$ for $2 \mathrm{~h}$. The membranes were stained with $0.1 \%$ toluidine blue. The quantitative measurement of AMPS was carried out according to Saito et al. (23).

Enzyme digestions. Testicular hyaluronidase (Seikagaku-Kogyo, Tokyo) digestion was carried out by the method described by Fransson and Roden (16). Heparitinase digestion (a gift from 
Seikagaku-Kogyo, Tokyo) was performed as described by Tokunaga et al. (26). Chondroitinase AC and ABC (Seikagaku-Kogyo, Tokyo) digestions were carried out by the method of Saito et al. (23). The unsaturated sugar mapping after digestion with chondroitinase $A B$ and $A B C$ was accomplished by cellulose thin layer chromatography (DC-Fettigplatten Cellulose-F, Merck, Germany) and the spots equivalent to $\Delta$ dichondroitin-4S (3-O-beta$\Delta-4,5$-glucuronosyl-N-acetyl-D-galactosamine-4-O- $\left.\mathrm{SO}_{4}\right)$ and $\Delta$ dichondroitin-6S (3-O-beta- $\Delta-4,5$-glucuronosyl-N-acetyl-D-galactosamine-6-O-SO $\mathrm{S}_{4}$ (authentic materials from Seikagaku-Kogyo, Tokyo) were extracted with $2 \mathrm{ml}$ of $0.01 \mathrm{M} \mathrm{HCl}$. Elution was carried out at $50^{\circ} \mathrm{C}$ for $10 \mathrm{~min}$. After centrifugation, the absorbance of supernatant solution was measured at $232 \mu$ against a reagent blank.

Determination of complexed carbohydrates in tissues. The quantitative analysis of complex carbohydrates in patient tissues was carried out by the method of Brunngraber et al. (5). This procedure allows the simultaneous quantitation of complex carbohydrates such as glycoproteins, glycosaminoglycans and glycopeptides.

Other chemical analysis. Hexose was determined by the orcinol method (15). Uronic acid content was determined by the carbazol method of Dische and Shettles (7). Hexosamine was measured after hydrolysis in $4 \mathrm{M} \mathrm{HCl}$ at $100^{\circ} \mathrm{C}$ for $15 \mathrm{~h} \mathrm{(19)}$ by the ElsonMorgan method (4) and on a Hitachi amino acid analyzer. Total sulfate was measured after hydrolysis with $4 \mathrm{M} \mathrm{HCl}$, using the $\mathrm{BaCl}_{2}$-gelatin turbidity method described by Dodgson and Price (9). Sialic acid was measured by the method of Svennerholm (25). Fucose was determined as described by Dische (8).

\section{RESULTS}

Urinary AMPS in MSD patients. Figure 1 shows the quantitative analysis of the total urinary excretion of AMPS in patients with MSD heterozygote carriers of MSD, Hunter, Sanfilippo and Morquio patients and from 10 normal control subjects. Excretion of

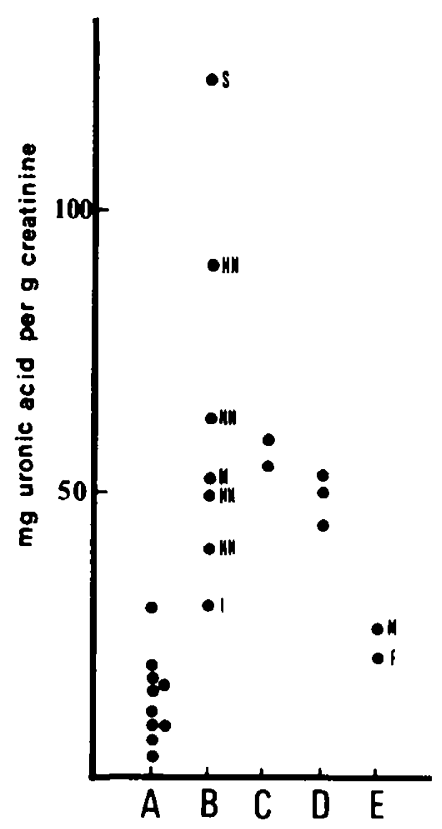

Fig. 1. Urinary acid mucopolysaccharide excretion in patients with MSD and its heterozygots, mucopolysaccharidoses, mucolipidosis and lipidosis. Lane $A$; control subjects, lane $B$, mucopolysaccharidoses and mucolipidosis (abbreviations used: S, Sanfilippo syndrome; HN, Hunter syndrome; $\mathrm{M}$, Morquio syndrome; and $\mathrm{I}$, I-cell disease), lane $C ; \mathrm{G}_{\mathrm{M}^{-}}$ gangliosidosis, lane $D$; MSD patient, lane $E$; MSD obligate heterozygote (M, patient's mother and $F$, patient's father). High values of uronic acid in $\mathrm{G}_{M 1-g a n g l i o s i d o s i s}$ are due to high hexose content by carbazol reaction. AMPS excreted in urines were expressed as $\mu \mathrm{g}$ uronic acid per $g$ creatinine.
MSD in the MSD patients' urine was 4-5 times higher than the controls, whereas the urinary AMPS excreted by MSD obligate heterozygotes was about twice that of control subjects. Urinary AMPS excretion by the MSD patient was quantitatively equivalent to that seen in patients with mucopolysaccharidosis. Crude urinary AMPS from all these subjects were subjected to cellulose acetate electrophoresis and determined quantitatively by the spectrophotometric method. The AMPS from the MSD patients contained major components with mobilities similar to authentic heparan sulfate $(50 \%)$ and chondroitin sulfate $\mathrm{A} / \mathrm{C}(50 \%)$. On the other hand, the mother of the MSD patient excreted dermatan sulfate, heparan sulfate and chondroitin sulfate $\mathrm{A} / \mathrm{C}, 36,18$, and $46 \%$, respectively, whereas the patient's father excreted only heparan sulfate and chondroitin sulfate $\mathrm{A} / \mathrm{C}, 21$ and $79 \%$, respectively. Control subjects excreted heparan sulfate and chondroitin sulfate A/C, 3-10 and $90-97 \%$ of the total AMPS, respectively.

The AMPS from control, MSD, Hunter and Sanfilippo patients were subjected for the fractionation of AMPS on a Dowex-1 column. Each AMPS fraction isolated from the Dowex-1 column chromatography was subjected for carbohydrate and analysis, performed by the orcinol, carbazol, Elson-Morgan methods, and hexosamine ratio by Hitachi amino acid analyzer (Table 1). It was also analyzed by cellulose acetate electrophoresis. The analytical data and findings with cellulose acetate electrophoresis of the AMPS indicated that excreted AMPS in MSD urine were heparan sulfate and chondroitin sulfate $A / C$. The identified heparan sulfate was completely digested by heparitinase and was resistant to testicular hyaluronidase and chondroitinase $\mathrm{ABC}$. The chondroitin sulfate $A / C$ fraction was completely digested by testicular hyaluronidase. Digestion by chondroitinase $\mathrm{AB}$ and $\mathrm{ABC}$ produced disaccharide 4-S and 6-S unsaturated sugar (57 and 43\%, respectively).

AMPS analysis in MSD patient's tissues. The carbohydrate composition of liver and brain from MSD and $\mathrm{G}_{\mathrm{M}_{1}-\text { gangliosidosis }}$ is shown in Table 2. In "the CPC-precipitable AMPS" fraction of MSD liver, AMPS measured by the carbazol reagent was 30-40 times higher than those of controls. In the "dialyzable oligosaccharides" fraction, the MSD patient liver contained approximately twice the amount of small oligosaccharide fragments probably derived from AMPS. "The non-dialyzable glycopeptides" fraction, obtained from MSD liver, was increased about 6 times when compared with the control valve. The $\mathrm{G}_{\mathrm{M}_{1} \text {-gangliosidosis tissue }}$ accumulated about 25 times the concentration of glycopeptides in controls. Accumulated AMPS in the MSD patient's cortical gray matter was 30-40 times that of controls as uronic acid content, whereas in the white matter it was only 5 times higher than controls. Hexosamine and uronic acid contents were increased about 2-6 times higher than those of controls in the "dialyzable oligosaccharides" fractions obtained from MSD gray matters. Fucose and sialic acid concentrations were not significantly altered in each fraction of brain and liver with MSD (data is not shown). The cellulose acetate electrophoretic patterns of crude AMPS isolated from the MSD patient's liver consisted predominantly of heparan sulfate with some increase of dermatan sulfate $(75,20 \%$ of total AMPS, respectively). The relative concentrations in normal liver of dermatan sulfate, chondroitin sulfate $A / C$ and heparan sulfate comprised 30,45 and $25 \%$, respectively. The heparan sulfate band was similar to the authentic standard in that it was not digested by testicular hyaluronidase and chondroitinase $A B C$ but digested completely by heparitinase. Further characterization of MSD liver AMPS was performed by fractionation with DowexI column chromatography. Major fraction of MSD liver AMPS was eluted from 1.25-1.5 M NaCl gradient. Each fraction was subjected to cellulose acetate electrophoresis and chemical analysis. The major peak eluted with $1.5 \mathrm{M} \mathrm{NaCl}$ was heparan sulfate with slightly increased dermatan sulfate and a trace of chondroitin sulfate $A / C$. The peak fraction eluted with $0.25 \mathrm{M} \mathrm{NaCl}$ was not AMPS because this fraction contained high amounts of hexose and hexosamine. Table 3 depicts the data of the chemical analysis of AMPS fractions isolated from Dowex-1 column chromatogra- 
Table 1. Chemical analysis of fractions eluted from Dowex-1 column chromatography in Hunter, Sanfilippo and MSD patients' urines. ${ }^{1}$

\begin{tabular}{|c|c|c|c|c|c|c|c|c|c|c|c|c|}
\hline \multirow[b]{2}{*}{ Fraction } & \multicolumn{4}{|c|}{ Hunter } & \multicolumn{4}{|c|}{ Sanfilippo } & \multicolumn{4}{|c|}{ MSD } \\
\hline & $\begin{array}{l}\text { Uronic } \\
\text { acid }^{2}\end{array}$ & Hexose $^{2}$ & $\begin{array}{l}\mathrm{C} / \mathrm{O} \\
\text { ratio }\end{array}$ & $\begin{array}{c}\text { GalNH }_{2} / \\
\text { glcNH }_{2}\end{array}$ & $\begin{array}{l}\text { Uronic } \\
\text { acid }\end{array}$ & Hexose & $\begin{array}{l}\mathrm{C} / \mathrm{O} \\
\text { ratio }\end{array}$ & $\begin{array}{c}\mathrm{GalNH}_{2} / \\
\mathrm{glcNH}_{2}\end{array}$ & $\begin{array}{l}\text { Uronic } \\
\text { acid }\end{array}$ & Hexose & $\begin{array}{l}\mathrm{C} / \mathrm{O} \\
\text { ratio }\end{array}$ & $\begin{array}{c}\text { GalNH }_{2} / \\
\text { glcNH }_{2}\end{array}$ \\
\hline $1(0.5 \mathrm{M} \mathrm{NaCl})$ & 0.89 & 1.93 & 0.46 & $9.9 / 90.1$ & 0.84 & 0.82 & 1.02 & $0.1 / 99.1$ & 1.66 & 1.17 & 1.42 & $13.1 / 86.9$ \\
\hline $2(0.75 \mathrm{M} \mathrm{NaCl})$ & 3.60 & 1.30 & 2.76 & $7.2 / 92.8$ & 2.65 & 0.61 & 4.34 & n.d. ${ }^{3}$ & 2.04 & 0.83 & 2.46 & $18.8 / 81.2$ \\
\hline $3(1.0 \mathrm{M} \mathrm{NaCl})$ & 3.82 & 1.16 & 3.29 & $21.4 / 78.6$ & 1.39 & 0.37 & 3.76 & n.d. & 1.62 & 0.70 & 2.31 & $30.7 / 69.3$ \\
\hline $4(1.25 \mathrm{M} \mathrm{NaCl})$ & 4.10 & 1.48 & 2.77 & $63.6 / 38.4$ & 1.05 & 0.29 & 3.62 & n.d. & 1.36 & 0.91 & 1.49 & $72.7 / 27.3$ \\
\hline $5(1.5 \mathrm{M} \mathrm{NaCl})$ & 3.82 & 3.67 & 1.04 & $70.4 / 29.6$ & 0.34 & 0.15 & 2.26 & n.d. & 0.94 & 0.56 & 1.67 & $78.9 / 21.1$ \\
\hline $6(1.75 \mathrm{M} \mathrm{NaCl})$ & 1.16 & 1.27 & 0.91 & $76.5 / 23.5$ & 0.10 & 0.11 & 0.91 & n.d. & 0.04 & 0.02 & 2.0 & $82.3 / 17.7$ \\
\hline $7(2.0 \mathrm{M} \mathrm{NaCl})$ & 0.54 & 0.79 & 0.68 & $80.1 / 19.9$ & 0.08 & 0.16 & 0.50 & n.d. & 0.08 & 0.05 & 1.6 & $81.7 / 18.3$ \\
\hline
\end{tabular}

'Values obtained from $150 \mathrm{ml}$ urine.

${ }^{2}$ Values for uronic acid and hexose are expressed as $\mu$ moles per fraction.

${ }^{3}$ Not determined.

${ }^{4} \mathrm{C} / \mathrm{O}$ ratio, carbazol to orcinol value ratio.

${ }^{5}$ galNH $_{2} /$ glcNH$_{2}$, galactosamine to glucosamine ratio.

Table 2. Carbohydrate compositions in gray matter, white matter and liver of patients with MSD, according to the method of Brunngraber $(5)^{1}$

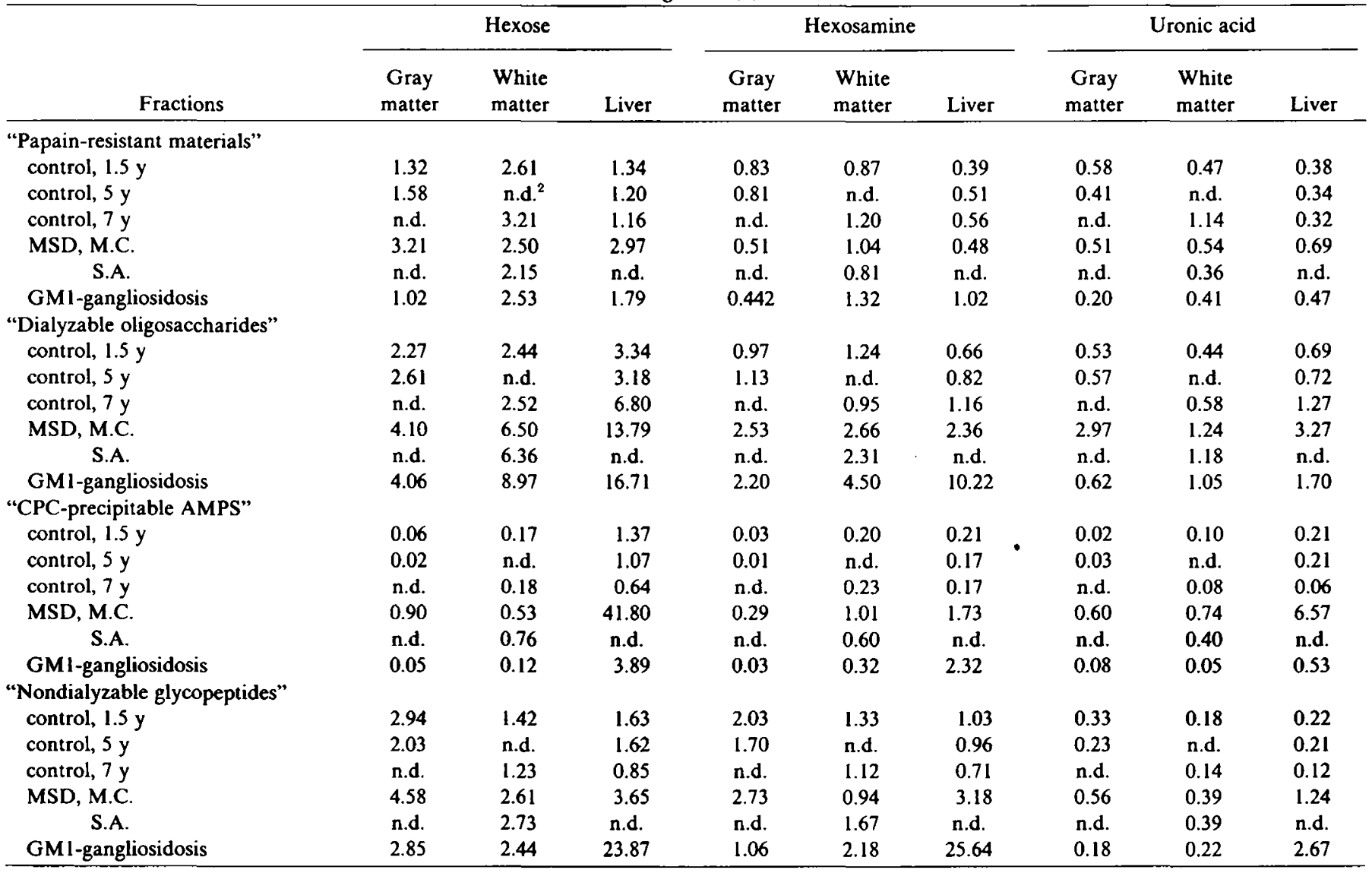

${ }^{1}$ Values are expressed as $\mu$ moles per $100 \mathrm{mg}$ dry tissues.

${ }^{2}$ Not determined.

${ }^{3} 1.5 \mathrm{y}, 5 \mathrm{y}$ and $7 \mathrm{y}$ indicate the age (years) of patients.

phy. The data indicate that major AMPS in MSD liver was heparan sulfate with a slight increase of dermatan sulfate.

\section{DISCUSSION}

AMPS metabolism in MSD patients has not been previously studied in detail. Bischel et al. (3) reported that a major compound excreted in MSD patient's urine and in the kidney might be heparan sulfate, whereas Rampini et al. (22) reported higher excretion of dermatan sulfate and heparan sulfate in two patients. Our case excreted heparan sulfate as the major AMPS with some increase in chondroitin sulfate $\mathrm{A} / \mathrm{C}$ in urine. Isolation and characterization of isolated AMPS by Dowex-1 column chromatography, enzyme digestion and chemical analysis confirmed that the major AMPS excreted were heparan sulfate and chondroitin sulfate $A / C$. The proportion of heparan sulfate and chondroitin sulfate $A / C$ was about $50 / 50$. The ratio of chondroitin sulfate $A$ to $C$ was $57 / 43$. The total excreted AMPS in MSD urine was equivalent to that seen in the other mucopolysaccharidoses such as Hunter, Morquio and Sanfilippo syndromes. In the heterozygotes, the mother of the patient excreted a higher proportion of dermatan sulfate with a relative increase of heparan sulfate, while 
Table 3. Chemical analysis of fractions eluted from Dowex-1 column chromatography in control and MSD liver

\begin{tabular}{|c|c|c|c|c|c|c|c|c|}
\hline Fraction & \multicolumn{4}{|c|}{ Control } & \multicolumn{4}{|c|}{ MSD } \\
\hline $2(0.5 \mathrm{M} \mathrm{NaCl})$ & $1.28(1.00,89 / 11)$ & $0.24(0.19)$ & $1.00(0.78)$ & 0.24 & $2.27(1.00,90 / 10)$ & $1.66(0.73)$ & $2.24(0.99)$ & 0.74 \\
\hline $3(0.75 \mathrm{M} \mathrm{NaCl})$ & $0.41(1.00,57 / 43)$ & $0.34(0.83)$ & $0.41(1.00)$ & 0.83 & $2.45(1.00,88 / 22)$ & $2.19(0.89)$ & $1.61(0.66)$ & 1.36 \\
\hline $4(1.0 \mathrm{M} \mathrm{NaCl})$ & $0.50(1.00,53 / 47)$ & $0.45(0.90)$ & $0.28(0.56)$ & 1.60 & $3.23(1.00,93 / 7)$ & $3.19(0.99)$ & $1.33(0.41)$ & 2.39 \\
\hline $7(1.75 \mathrm{M} \mathrm{NaCl})$ & $0.11(1.00,80 / 20)$ & $0.10(0.91)$ & $0.17(1.55)$ & 0.50 & $3.15(1.00,78 / 22)$ & $2.55(0.81)$ & $1.16(0.37)$ & 2.20 \\
\hline $8(2.0 \mathrm{M} \mathrm{NaCl})$ & - & - & - & - & $2.12(1.00,48 / 52)$ & $1.40(0.66)$ & $1.05(0.50)$ & 1.33 \\
\hline
\end{tabular}

'Values are expressed as $\mu$ mole $/ 10 \mathrm{~g}$ wet tissues.

${ }^{2}$ glcNH$_{2} /$ galNH$_{2}$, glucosamine to galactosamine ratio.

${ }^{3}$ The parenthesis indicates values when hexosamine ratio was 1.00

${ }^{4} \mathrm{C} / \mathrm{O}$ ratio carbazole to orcinol ratio.

the father excreted a relatively increased heparan sulfate. The increase of dermatan and heparan sulfate in the MSD mother suggests that the gene for sulfoiduronate sulfatase is located on the X-chromosome.

The chemical analysis of AMPS in MSD patients' tissues reported here demonstrated that MSD liver accumulated predominantly heparan sulfate, while brain tissue contained increased heparan and dermatan sulfate. Bischel et al. (3) reported the accumulation of glycosaminoglycans in kidney, possibly heparan sulfate and Murphy et al. (20), using ethanol precipitation methods, reported the accumulation of heparan and dermatan sulfate in the liver of two cases of MSD. However, neither detailed chemical analysis of AMPS in this disorder described in this study nor quantitation of the degree of accumulation of AMPS in MSD tissues have been reported previously. As shown in Table 2, a 3050-fold increase in AMPS is observed in liver, a 30-fold increase in gray matter and a 5-fold increase in white matter.

Structural analysis of hepatic AMPS identified the major accumulated compound as heparan sulfate and a fraction consisting of chondroitin sulfate $\mathrm{A} / \mathrm{C}$.

In conclusion, the chemical analysis of AMPS in MSD urine and in tissues from two cases indicates that the major accumulated compound in this disorder is heparan sulfate rather than dermatan sulfate. In MSD, heparan sulfate $\mathrm{N}$-sulfatase, glucosamine-6-sulfatase and alpha-iduronosulfatase for the degradation of heparan sulfate have been described to be deficient $(2,10)$. It seems that pronounced accumulation of heparan sulfate rather than dermatan sulfate in MSD liver and urine arises due to the triple enzyme deficiencies or simply due to tissue-specific AMPS metabolic defects by several sulfatase deficiencies. Further exact explanation in this regard could be brought by how much degree of the enzyme deficiencies de novo in MSD tissues.

The accumulation of heparan sulfate in MSD tissues, probably in lysosomes, is the primary cause of organomegaly such as hepatosplenomegaly and of mental retardation (17).

Recently, Fiddler et al. (14) reported that this disorder is probably caused by reduced enzyme activity of normal enzymes and not by quantitatively abnormal enzymes. The nature of multiple enzyme deficiencies for the degradation of ASPS is still puzzling.

\section{REFERENCES AND NOTES}

1. Austin, J., Armstrong, D., and Shearer, L.: Metachromatic form of diffuse cerebral sclerosis (metachromatic leukodystrophy; MLD) V. The nature and significance of low sulfatase activity: a controlled study of brain, liver and kidney in four patients with MLD. Arch. Neurol., 13: 593 (1965).

2. Basner, R., von Figura, K., Glössl, J., Kresse, H., and Mlekusch, W.: Multiple deficiency of mucopolysaccharide sulfatases in mucosulfatidosis. Pediatr. Res., 13: 1316 (1979).

3. Bischel, M., Austin, J., and Kemeny, M.: Metachromatic leukodystrophy VII. elevated sulfated acid mucopolysaccharide levels in urine and postmortem tissues. Arch. Neurol., 15: 13 (1966).
4. Boas, N. F.: Method for the determination of hexosamines in tissues. J. Biol. Chem., 204: 553 (1953).

5. Brunngraber, E. G., Brown, B. D., and Aguilar, V.: Isolation and determination of non-diffusible sialofucohexosaminoglycans derived from brain glycoproteins and their anatomical distribution in bovine brain. J. Neurochem., 16: 1059 (1969).

6. DiFerrante, N.: Acid mucopolysaccharides of normal human urine. J. Lab. Clin. Med., 61: 633 (1963).

7. Dische, Z. and Shettles, L. B.: A specific color reaction of methylpentoses and a spectrophotometric micromethod for their determination. J. Biol. Chem., 175: 595 (1948).

8. Dische, Z.: A new specific color reaction of hexouronic acids. J. Biol. Chem., 167: 189 (1974)

9. Dodgson, K. S. and Price, R. G.: A note on the determination of the ester sulfate content of sulfated polysaccharides. Biochem. J., 84: 106 (1962).

10. Eto, Y., Wiesmann, U. N., Carson, J. H., and Herschkowitz, N. N.: Multiple sulfatase deficiency in cultured skin fibroblasts: occurrence in patients with a variant form of metachromatic leukodystrophy. Arch. Neurol., 30: 153 (1974).

11. Eto, Y., Rampini, S., Wiesmann, U. N., and Herschkowitz, N. N.: Enzymic studies of sulfatases in tissues of the normal human and in metachromatic leukodystrophy with multiple sulfatase deficiencies; arylsulfatases A, B and C, cerebroside sulfatase, psychosine sulfatase and steroid sulfatases. J. Neurochem., 23: 1161 (1974).

12. Eto, Y.. Meir, C., and Herschkowitz, N. N.: Chemical compositions of brain and myelin in two patients with multiple sulfatase deficiency (A variant form of metachromatic leukodystrophy). J. Neurochem., 27: 1071 (1976).

13. Eto, Y., Numaguchi, $S$. and Handa, $T$.: in preparation, 1981

14. Fiddler, M. B., Vine, D., Shapira, E., and Nadler, H. C.: Is multiple sulfatase deficiency due to defective regulation of sulphohydrolase expression? Nature, 282: 98 (1979).

15. Francois, C. Marshall, R. D., and Neuberger, A.: Carbohydrates in protein. 4. The determination of mannose in hen's egg albumin by radioisotope dilution. Biochem. J., 83: 335 (1962).

16. Fransson, L. A. and Roden, L. J.: Structure of dermatan sulfate. I. degradation of testicular hyaluronidase J. Biol. Chem., 242: 4161 (1967).

17. Kresse, H.: Mucopolysaccharidosis III A (Sanfilippo A syndrome): deficiency of heparan sulfamidase, deficiency in cultured skin fibroblasts and leukocytes. Biochem. Biophys. Res. Commun., 54: 1111 (1973).

18. Murata, K., Harada, T., Fujiwara, T., and Funahashi, T.: Chondroitin sulfate isomers in normal human urine. Biochim. Biophys. Acta, 230: 583 (1971).

19. Murata, K.: Acidic glycosaminoglycans in human kidney tissue. Clin. Chim. Acta, 63: 157 (1975)

20. Murphy, J. V.. Wolfe, J. V., Balasz, E., and Moser, H. W.: A patient with deficiency of aryisulfatase A, B, C and steroid sulphatases, associated with storage of sulfatide, cholesterol sulfate and glycosminoglycans. In: Lipid Storage Disorders; Enzymatic Defects and Clinical Implications, Ed. Bernsohn J. and Grossman, p. 67. (Academic Press, New York, NY 1971).

21. Neufeld, E. F., Liebaers, L., and Lim. T. W.: Iduronate sulfatase determination for the diagnosis of Hunter syndrome and the detection of the carrier state. Advances in Experimental Medicine and Biology. Vol. 68, "Current Trends in Sphingolipidoses and Allied Disorders" (ED. Volk B. W. and Schneck L.) p. 253. Plenum Press, New York, NY, 1976.

22. Rampini, S., Isler, W., Baerlocker, K., Bischoff, A., Ulrich, J., and Plüss, H.: Die Kombination von metachromatischer Leukodystrophie und Mucopolysaccharidose als selbstpauandiges Krankheitbild (Mukosulfatidose). Helv. Paediatr. Acta, 25: 436 (1970).

23. Saito, H., Yamagata. T., and Suzuki, S.: Enzymatic methods for the determination of small quantities of isomeric chondroitin sulfates. J. Biol. Chem., 243: 1536 (1968).

24. Schiller, S., Slover, G. A., and Dorfman, A.: A method for the separation of acid mucopolysaccharides. Its application to the isolation of heparin from the skin of rats. J. Biol. Chem., 236: 983 (1961). 
25. Svennerholm, L.: Quantitative estimation of sialic acids. II. A colorimetric resorcinol-hydrochloric acid method. Biochim. Biophys. Acta, 24: 604 (1957)

26. Tokunaga, M., Wakamatsu, E., and Yoshizawa, Z.: Increased excretion of urinary glycosaminoglycans in a case of Rothmund Thompson syndrome. Tohoku J. Exp. Med., 126: 1 (1978).

27. Wessler, E.: Analytical and preparative separation of acidic glycosaminoglycans by electrophoresis in barium acetate. Anal. Biochem., 26: 436 (1968).
28. This research was supported by grants by Nanbyo and Acid mucopolysaccharide storage disease program from a Ministry of Education.

29. Requests for reprints should be addressed to Yoshikatasu Eto, M.D., Department of Pediatrics, Tokyo Jikei University School of Medicine, Nishishinbashi 3-25 8, Minato-ku, Tokyo, Japan (105).

30. Received for publication September 23, 1980

31. Accepted for publication September $28,1980$.

Copyright $(\mathcal{C} 1982$ International Pediatric Research Foundation, Inc. 0031-3998/82/1605-0395\$02.00/0

\section{Erratum}

In the article by Stanley et al. entitled "Intragastric Feeding in Type I Glycogen Storage Disease: Factors Affecting the Control of Lactic Acidemia" in Pediatric Research 15: 1504 (1981) the formula on page 1505 was incorrectly printed. The formula, appearing on line 11, should read:

$$
\mathrm{Y}(\mathrm{mg} / \mathrm{min})=0.0014 \mathrm{X}^{3}-0.214 \mathrm{X}^{2}+10.411 \mathrm{X}-9.084
$$

We regret the error. 